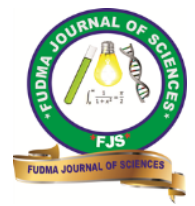

FUDMA Journal of Sciences (FJS)

ISSN online: $2616-1370$

ISSN print: 2645 - 2944

Vol. 4 No. 3, September, 2020, pp $107-113$

DOI: https://doi.org/10.33003/fjs-2020-0403-275

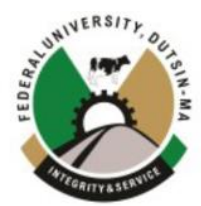

\title{
ANALYSIS OF GEO-SPATIAL DATABASE AND DISTRIBUTION OF GOVERNMENT SECONDARY SCHOOLS' USING GIS IN CHIKUN LOCAL GOVERNMENT AREA, KADUNA STATE
}

Doyani, B. I., Inusa, M., Ayuba, B., Bulus, S. J., and Danjuma, E. S.

Directorate of Professional Diploma in Education, Federal College of Education, Zaria, Kaduna, Nigeria

*Corresponding Author's Email: iliyababaraus@gmail.com, babsite4god@gmail.com

\begin{abstract}
Provision of education as a global social service is champion by the public sector. Where these education facilities are located influences their utilization and efficiency. Proximity to these facilities also influences decisions to seek and patronize them. The study analyzes the geo-spatial database and distribution of Government Secondary Schools, using GIS in Chikun Local Government Area. 28 Government Secondary Schools were identified. Their geographic coordinates were established by the use of GPS device and mapped out. The data generated from the field was used to create geo-database of Government Secondary Schools. From the study, $51.4 \%$ of registered students were enrolled in the Government Junior Secondary Schools cadre while 58.6\% was in Government Senior Secondary Schools. 79\% of the student's enrolments were concentrated in three communities. Nasarawa community was $43.3 \%$, Sabo-Tasha community was $19.4 \%$ and Narayi community was $16.5 \%$. These communities form part of Kaduna metropolis with evidence of high population concentration. Queries from the database show only $21.4 \%$ of the Schools were with fenced, $7.1 \%$ of the schools were with school halls, $25 \%$ of the schools were with school libraries and $14.3 \%$ of the schools were with computers. The distribution pattern was found to be appearing not different than random using the ArcGIS auto-correlation analysis tool. Government Secondary Schools in the study area appear to be poorly equipped for conducive learning experience. Therefore, the study recommends schools expansion, provision of new schools and upgrading existing schools to standard by all stakeholders.
\end{abstract}

Keywords: Geographic-coordinates, geo-database, mapping, spatial distribution, government secondary schools.

\section{INTRODUCTION}

In most of the advancing economy of the world, human resources and education is crucial for development of civilization driving economy. Nations development and civilization depends primarily on its ability to utilize her intellectual resources at their disposal (Kinda, 2017). This makes education vital and mandatory for all nations who want to attain viable economy status. Education is strongly advocated by promoters of social equality, social justice and modern day democracy; who view it as a way for advancing development at a competitive edge. It also provides opportunities to the general public and can be measured and evaluated in terms of spatial, social, political and economic dimensions (Ogunyemiet al., 2014;Juneitt, 2015). Therefore, access to education is a human right issues and development programme meant for economic transformation and liberation. One thing for grab is that, the overall impact of education for national development will guarantee quantity and quality of human resources needed for the economic growth and development of any nation.

Officially, formal education occurs in schools with infrastructural facilities and friendly environment where effective learning take place between the facilitator and the target audience (Sunday and Olayiwola, 2018). But in the past, the elites in Nigeria, and other African countries has used access to education as political and economic tool to suppress and uplift a section of the population over the other (Fabiyi and Ogunyemi, 2015). This is often attributed to the fact that, there exist income inequalities in most countries. It is sad to know that same injustice on social and economic drivers is still taking place in Nigeria today. The wide array of social inequalities of education has been a debated issue within the social sciences as well as the teaching profession. Discrimination of various kinds such as religion, politics, ethnic, racial, and gender are very often the main issues of debate. However, territorial inequalities of education are discussed far less, despite the facts that these differences exist in great extremes, and attempts to resolve them have yielded very little (Healey, 2008; Humphreys and Crawfurd, 2014). Unless the various stakeholders are willing to accommodate the fact as promulgated by Ibara (2019) that, the overall development strategy of education in any given society depends largely on the level at which there is an equitable distribution of educational resources and opportunities to all.

In Nigeria, especially the northern region, the provision of education facilities is typically concentrated in settled centers with higher hierarchical order (Umar et al., 2016). In other words, there are more educational facilities in towns and cities than in rural settlements where only elementary schools are found. Inhabitants of core urbanized areas thus have better access to education than the poor inhabitants of remote rural peripheries. These practices are against what Barro and Jongwa. (2000) emphasized on the provision of education as a social service for all around the world, placing valid demands for government and interest stakeholders to do more in this regard. Secondary education is designed for the public after elementary schooling. It begins generally at the age of eleven 
to sixteen years. Some secondary education, such as vocational schooling, is terminal and prepares the student for employment upon graduation. Others lead to advanced training in colleges, universities, or technical schools. The emphasis on educational services is based on the total dependence of development and policy actualization on the level of education in our society. If educational services are not adequately provided and sustained, it leads to poor and usable information in the system but if adequately provided and sustained, it provides the citizenry with information which can be used for effective and sustainable planning and management of their resources (Ige, 2013).

Chikun Local Government Area of Kaduna State Nigeria, form part of Kaduna metropolis with it headquarters is in Kujama. It has an area of $4,666 \mathrm{~km}^{2}$, and currently has a projected population of 535,727 in2020 base on 2006 population census used as beginning (NPCN and NBS, 2016). The problem with secondary education in the study area is not limited to provision of public secondary schools only but unbalance location and equipping of these facilities. Secondary education facilities has witness much pressure in recent years due to population explosion without corresponding expansion of existing and provision of new secondary schools and planning. Unless there is a tool to help decision makers in locating of schools base on approved standardized criterion, it will be abysmal planning for balance in the education sector. This is emphasized by Murray (2002) and Gangwar (2013) that location analysis approaches which assist planning processes continue to be important in both the public and private sectors given the costs and viability implications involved. Therefore, a deliberate effort is needed to balance the disparities by means of adequate distribution of public secondary schools within the study area. The study aim is to analyze geo-spatial database and distribution of public secondary schools at local government level, using GIS capabilities and different possibilities techniques.GIS application do support timely decision making, school mapping, operations for educational planning, enforcing clear school planning policies, and finding the best locations for existing and new services, service analysis, and creation of digital database. Stakeholders in education should take advantage of GIS tool for planning and management purposes (Senapathi and Paramasivam, 2019; Burrough, 2001). The study area is imperative and provided a framework and a guide for facility planning and management.

\section{MATERIALS AND METHODS}

Materials and equipments used for this study are administrative map of Chikun local government area sourced from Kaduna state ministry of lands and survey,76C5X Handheld GPS receiver for acquisition of geographic coordinates of public secondary schools, Laptop that houses Microsoft Excel, Words and ArcGIS 10.3, for data processing, manipulations and GIS operations, checklist of all government secondary schools sourced from the local government head office, Kujama that served as guide for ground truthing. Questionnaires were administered to all principals of public secondary schools to authenticate the information received from the local government head office such as school name, address, number of students in each school, number of schools with fenced etc., secondary data from existing literature, journals, seminar papers, reports, thesis, and conference proceedings were used to enrich the study. A combination of descriptive and GIS analysis was employed. The coordinates and other relevant attributes generated from field survey was copied in Microsoft excel and saved as CSV (comma delimited) format. It was imported into GIS environment 'ArcGIS 10.3' using the add $\mathrm{XY}$ command at the tools menu. The coordinates of each school was used to determine absolute locations of public secondary schools of the study area. This was done by overlaying the coordinates of the schools on the geo-referenced digitized map by a process known as point on polygon overlay. The map overlaid with the schools coordinates formed composite maps showing the distribution of public secondary schools of the study area. A spatial database was created using ArcGIS 10.3 software based on the attribute data derived from the coordinates, questionnaires and the checklist. The database was created by adding required number of fields (columns) to the table and entering the data for each school in their corresponding records (rows) of data attributes collected. A table was created in Microsoft Excel and saved as CSV (comma delimited) format which is recognized and accepted by the ArcCatalog extension of ArcGIS. The file is imported into Arc Map environment using the add XY Command at the tools menu for analysis. Updates and changes can be effected in any school attribute as well as adding more attributes in the ArcGIS interface by an authorized ArcGIS application user. The system created allows queries and updates. For the analysis of the distribution pattern of the public secondary schools, autocorrelation analysis was used to evaluate whether the spatial patterns of schools are clustered, dispersed or random. Using the ArcGIS 10.3 spatial statistic tools: the Moran's I value, the $\mathrm{Z}$ score or $\mathrm{P}$ value was calculated to assess the index. A Moran's I value close to +1.0 indicates clustering, while a value close to -1.0 indicates dispersion.

\section{RESULTS AND DISCUSSION}

Of the 28 Government Secondary Schools examined in the study area, 13 are Government Junior Secondary Schools and 15 are of the Senior Secondary Schools cadre. They are designed to service 22 communities out of several communities. The enrolments register of students at the time of study was 43,737 (100\%) with $51.4 \%$ students enrolled in the Government Junior Secondary Schools and 58.6\% students enrolled in Government Senior Secondary Schools. Nasarawa, Sabon-Tasha and Narayi Government Schools constituting $79 \%$ of students' enrollment. Furthermore, Nasarawa community had the highest students' enrolment of $43.2 \%$ with Government Junior Secondary School Nasarawa 21.9\% while Government Senior Secondary School Nasarawa was $21.3 \%$. Sabon-Tasha community had student enrolment of $19.4 \%$ with Government Junior Secondary School Sabon-Tasha 10.2\% while Government Senior Secondary Sabon-Tasha was 9.2\%.Narayi community student's enrolment was $16.5 \%$ with Government Junior Secondary Schools Narayi 9.8\% while Government senior secondary schools, Narayi had $6.7 \%$. Base on the analysis above, it is pertinent to note that, the three communities are located in the heart of Kaduna metropolis where rural-urban migration is on an increasing rate. Another key observation during the field was that most of these schools with higher population operate two schools in a single school concept. This suggest two things, either there is no space for expansion or stakeholders not willing to site new schools in the said communities. On the other part of the analysis, Government secondary schools with student enrolment of less 
than 1 or equal to 1 are mostly located in rural communities learning. Below is the database display. and are schools with the worse facilities for conducive.

Table 1: Geo-spatial database of Government secondary school, Chikun Local Government Area

\begin{tabular}{|c|c|c|c|c|c|c|c|c|c|c|c|c|c|c|c|}
\hline \multicolumn{16}{|c|}{ Table } \\
\hline & | 歁. & 田钧口 & 4] $x$ & & & & & & & & & & & & \\
\hline \multicolumn{16}{|c|}{ Secondary Schools } \\
\hline & OBJECTID & LATITUDE & LONGITUD & NAMES_OF_SCHO & SCH_ENR & LIBRAR & FENCE & HAL & BIO_LA & PHY_LA & CHEM_L & HM_ECON_L & COMPTE & TOLET & Shape * \\
\hline \multirow[t]{28}{*}{, } & 1 & 10.593691 & 6.890736 & GJSS Baba Savra & 218 & 0 & No & No & NO & No & NO & No & No & YES & Point \\
\hline & 2 & 10.271147 & 7.106161 & GJSS Chikun & 167 & 0 & NO & NO & No & NO & NO & No & No & YES & Point \\
\hline & 3 & 10.368775 & 7.399594 & GJSS Kakav & 377 & 0 & NO & NO & NO & No & NO & No & No & YES & Point \\
\hline & 4 & 10.368775 & 7.399594 & GSS Kakav & 323 & 0 & NO & NO & No & NO & NO & No & No & YES & Point \\
\hline & 5 & 10.333175 & 7.518947 & GJSS Kankomi & 233 & 0 & NO & NO & NO & NO & No & No & No & YES & Point \\
\hline & 6 & 10.518715 & 7.105977 & GJSS Kasaya & 118 & 0 & NO & NO & NO & NO & No & No & NO & YES & Point \\
\hline & 7 & 10.457831 & 7.624297 & GJSS Kujama & 485 & 0 & YES & NO & No & NO & NO & No & No & YES & Point \\
\hline & 8 & 10.457831 & 7.624297 & GSS Kujama & 448 & 0 & YES & NO & NO & NO & NO & No & No & YES & Point \\
\hline & 9 & 10.383242 & 7.491764 & GJSS Kidunv & 283 & 0 & No & NO & NO & NO & NO & No & No & YES & Point \\
\hline & 10 & 10.469981 & 7.449911 & GJSS Narayi & 41300 & 1 & YES & NO & NO & NO & NO & No & YES & YES & Point \\
\hline & 11 & 10.469981 & 7.449911 & GSS Narayi & 3004 & 1 & YES & NO & NO & NO & NO & No & YES & YES & Point \\
\hline & 12 & 10.480914 & 7.3981 & GJSS Nassarawa & 9621 & 0 & NO & NO & NO & NO & NO & No & YES & YES & Point \\
\hline & 13 & 10.480914 & 7.3981 & GSS Nassarawa & 9191 & 0 & NO & NO & NO & NO & No & No & YES & YES & Point \\
\hline & 14 & 10.400511 & 7.494297 & GJSS Rido & 469 & 0 & NO & NO & NO & NO & NO & No & NO & YES & Point \\
\hline & 15 & 10.441509 & 7.454191 & GJSS Sabon Tasha & \begin{tabular}{l|l}
4444 \\
\end{tabular} & 1 & YES & YES & NO & NO & NO & No & NO & YES & Point \\
\hline & 16 & 10.441509 & 7.454191 & GSS Sabon Tasha & 4010 & 1 & YES & YES & NO & NO & NO & No & No & YES & Point \\
\hline & 17 & 10.429208 & 7.416811 & GJSS Ungwan Romi & 1430 & 1 & No & No & No & No & NO & No & No & YES & Point \\
\hline & 18 & 10.429208 & 7.416811 & GSS Ungwan Romi & 1105 & 1 & No & NO & NO & NO & NO & No & No & YES & Point \\
\hline & 19 & 10.475975 & 7.488456 & GSS Bagado & 116 & 0 & NO & NO & NO & NO & NO & No & NO & YES & Point \\
\hline & 20 & 10.250244 & 7.229972 & GSS Gwagwada & 299 & 0 & NO & NO & NO & NO & NO & No & No & YES & Point \\
\hline & 21 & 10.427281 & 7.384458 & GsS Gonin Gora & 1179 & 0 & NO & NO & NO & NO & NO & No & No & YES & Point \\
\hline & 22 & 10.480525 & 7.378553 & GSS Kudendan & 233 & 1 & NO & NO & No & No & No & No & NO & YES & Point \\
\hline & 23 & 10.420931 & 7.534425 & GSS Maraba Rido & 311 & 0 & NO & No & NO & No & NO & No & NO & YES & Point \\
\hline & 24 & 10.318756 & 7.387847 & GSS Sabon Gayan & 376 & 0 & NO & NO & NO & NO & NO & No & NO & YES & Point \\
\hline & 25 & 10.453931 & 7.4775 & GSS Ungwan Baro & 153 & 0 & NO & NO & NO & NO & No & No & NO & YES & Point \\
\hline & 26 & 10.6169 & 7.2316 & GJSS Buruku & 348 & 0 & NO & NO & NO & NO & NO & No & NO & YES & Point \\
\hline & 27 & 10.282 & 7.412 & GSS Udawa & 245 & 0 & NO & NO & NO & NO & NO & No & NO & YES & Point \\
\hline & 28 & 10.666585 & 6.716264 & GSS Kuriga & 214 & 0 & NO & NO & No & NO & NO & No & No & YES & Point \\
\hline
\end{tabular}

From table 1, the Geo-database created allows us to perform different queries. For example, Government Secondary Schools without fence? Government Secondary Schools without hall? Government Secondary Schools with library? Government Secondary Schools with computers? etc. Below is the pop up results generated from the database on Government Secondary Schools without fence of the study area. 
Table 2: Government secondary schools without fence in Chikun LGA.

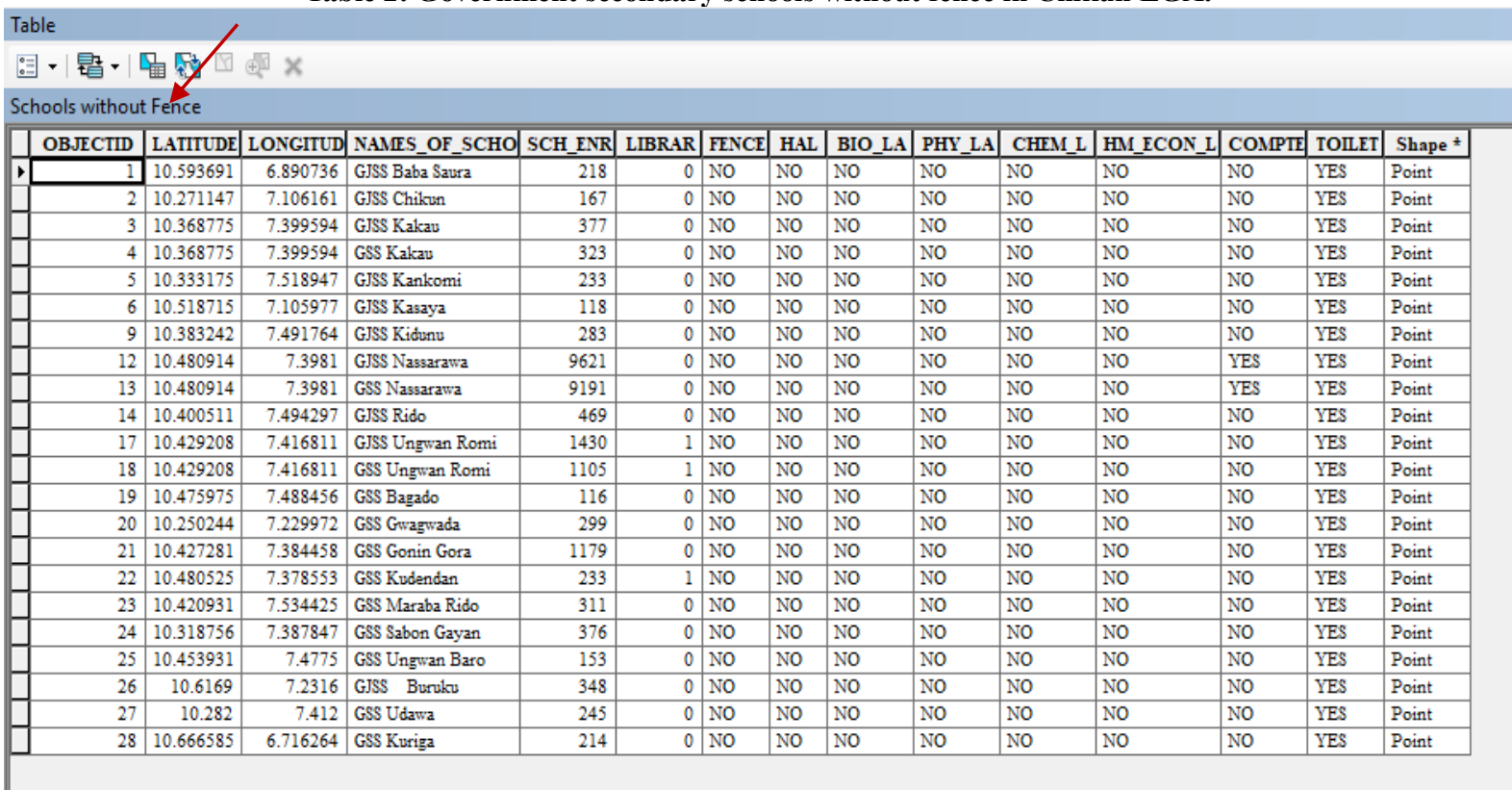

Result from table 2 display government secondary schools without fence indicating22 (78.6\%) public secondary schools are without fence with majority of them located in the rural communities. This invariably suggest that, only $6(22.4 \%)$ of public secondary schools are with fenced and are mostly located within Kaduna metropolis.

Another query was performs on "public secondary schools with school library" in the study area. The result display indicates that, only $25 \%$ of the public secondary schools has library while $75 \%$ coexist with no libraries. This also suggests how schools reading culture is fading in our places of learning. Below is the result display. 


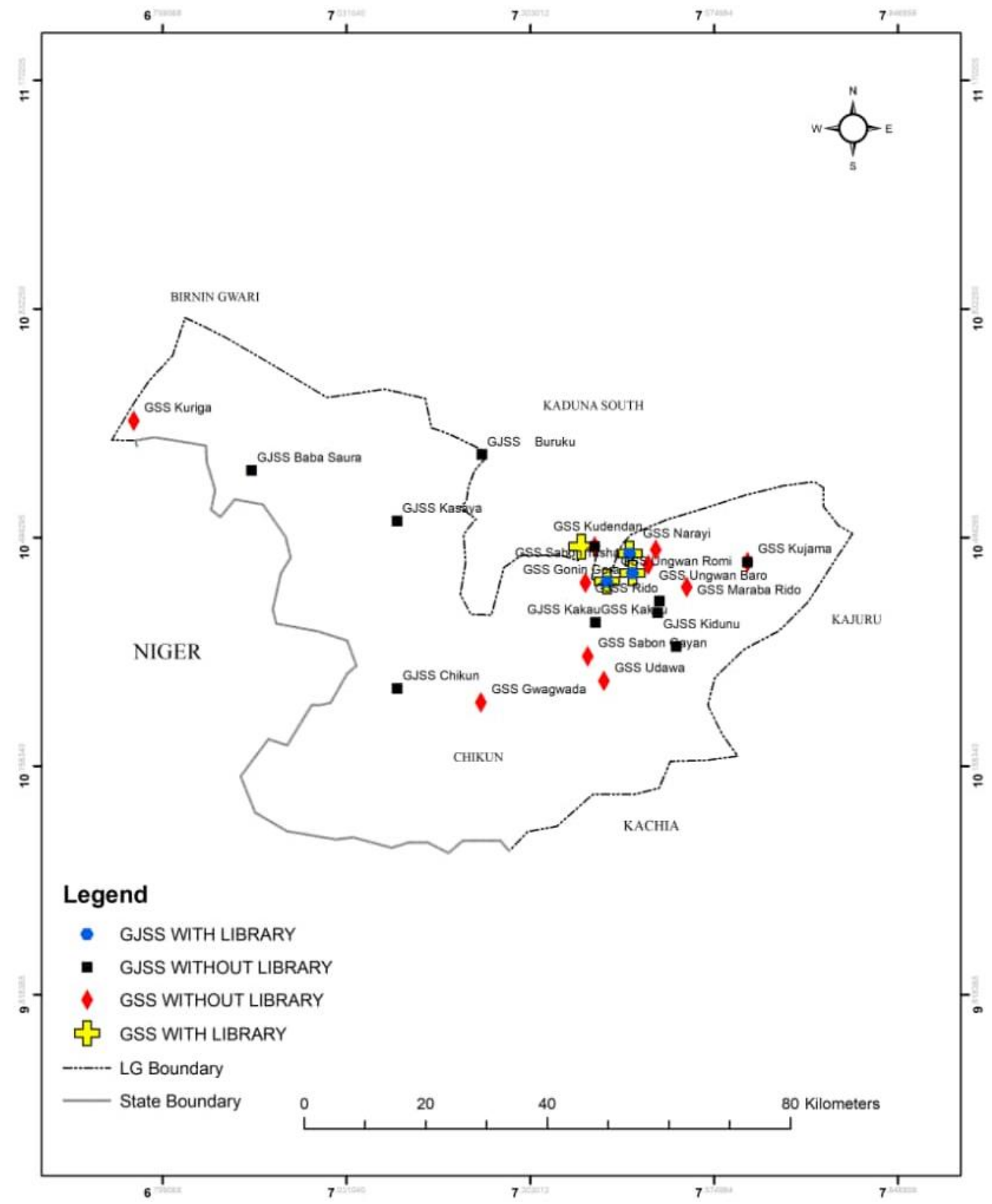

Figure 1: Government secondary schools with libraries of the study area

For the analysis of spatial pattern of public secondary schools, using the ArcGIS 10.3 auto-correlation statistical tool, the result from the report shows the following values: Moran Index value 0.337162 , Z score 1.022555 and $P$ value 0.267279 . Given the Zscore value is 1.02 , the pattern of distribution does not appear to be significantly different than random

The result from the report for the public secondary schools shows the following values: Moran Index value $0.337162, \mathrm{Z}$ score 1.022555 and $P$ value 0.267279 . Given the $\mathrm{z}$-score of 1.04 , the pattern does not appear to be significantly different than random. 


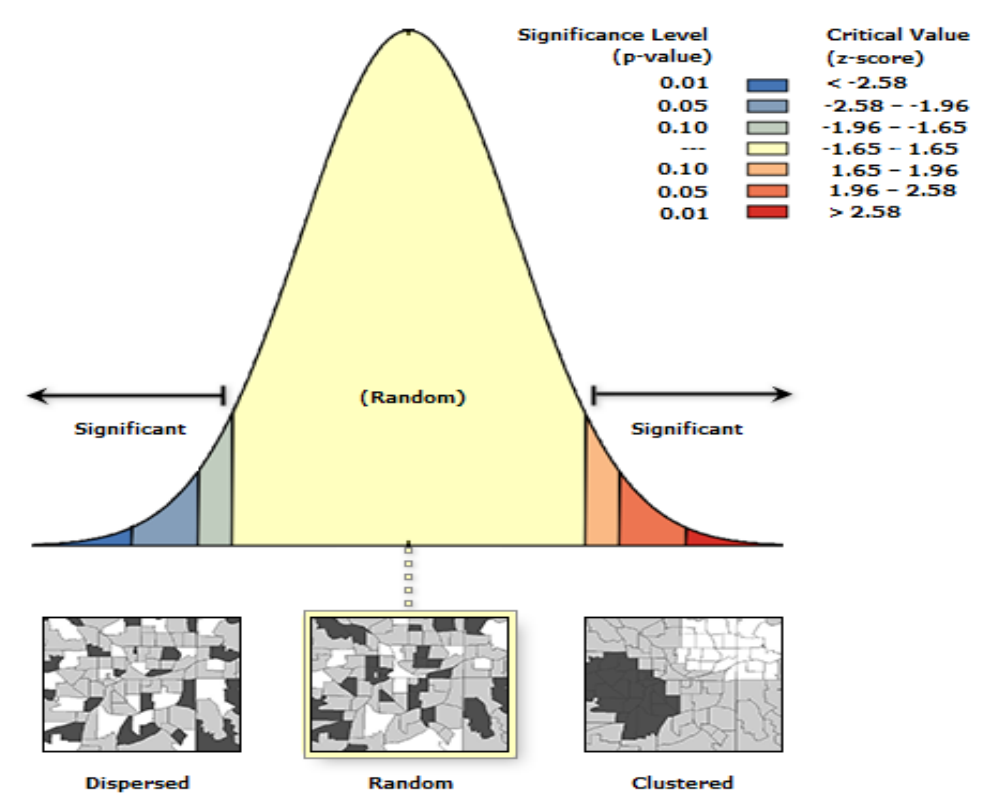

\section{CONCLUSION}

Finally to analyze Geo-spatial database and distribution pattern of public secondary schools using GIS in Chikun Local Government Area is imperative, considering how important GIS play in our modern world. The study was able to demonstrate the dynamic capabilities and possibilities of GIS application in spatial distribution and geo-database analysis This work could serve as a guide for decision making, policy making, planning and implementation of different programmes within the overall educational sector. The study also revealed 28 public secondary schools in the study area, but only few was found to be equipped to guarantee sound learning environment. More so, the database created allows different queries to be generated such as government schools without fence, schools without library etc. The auto-correlation analysis also revealed that the distribution pattern of Government secondary schools is not different than random. Finally the study recommends expansion of some existing Government secondary schools and provision of additional government secondary schools especially in Kaduna metropolis. The Government should equip all government secondary schools not minding their rural locations or urban to provide sound learning atmosphere for students and teachers.

Acknowledgement: The authors appreciate the management and staff of Kaduna State ministry of education, local government staff of Chikun local government area and to the anonymous reviewers for taking their time to improve this article.

\section{REFERENCES}

Barro, R. and Jong-Wha, L. (2000). International data on educational attainment. updates and im- plications. NBER working paperpp. 79-11.

Burrough, P.A. (2001). GIS and Geostatistics: essential partners for spatial analysis. 8.10.1023/A:1012734519752.
Fabiyi, O.O and Ogunyemi, S.A (2015). spatial distribution and accessibility to post primary educational institution in Ogun state, Southwestern Nigeria: case study of Yewa south local government area, Nigeria. 'Journal of Scientific Research and Reports5(7): 542-552

Gangwar, S. (2013). Geographical Information System (GIS) in Geography: A Conceptual Analysis. International Journal of Information and Computation Technology, 3(7), 723-728

Healey, R.G. (2008). Database management systems. In Maguire D J, Goodchild M F, Rhind D.W (eds) Geographical information systems: principles and applications. Harlow, Longman/New York, John Wiley \& Sons Inc. pp 251-267

Humphreys,S.and Crawfurd, L. (2014). EDOREN (Education data, research and evaluation in Nigeria) Review of the literature on basic education in Nigeria: Issues of access, quality, equity and impact, Nigeria, Federal Ministry of Education 6 (2): 36-41

Ibara, C. E. (2019). Politics of School Mapping: Evaluation of Spatial Distribution of Public Secondary Schools in Rivers State, Nigeria. Asian Research Journal of Arts \& Social Sciences, 8(4), 1-11. https://doi.org/10.9734/arjass/2019/v8i430111

Ige, A.M. (2013). Provision of secondary education in Nigeria: Challenges and way forward.Journal of African Studies and Development Vol. 5(1), pp. 1-9, DOI: 10.5897/JASD11.058

Juneitt, M. (2015). The efficiency of the spatial distribution of primary schools in AlAzizia district, in Journal of Wasit for Human Science, 11 (29): 533-569.

Kinda, W. (2017). The spatial distribution of the basic education schools in Lattakia City, Syria. Journal of education and social research, 7 (1): 106-109 
Kinda, W. (2017). The spatial distribution of the basic education schools in Lattakia City, Syria. Journal of education and social research, 7 (1): 106-109

Murray, A.L. (2002), "Site placement uncertainty in location analysis", available

http://gisknowledge.net/topic/problem_solving_and_decision_ making/murray_ceus_03.pdf (accessed 5 May 2018).

National Population Commission of Nigeria,and National Bureau of Statistics. (2016): https://www.citypopulation.de/php/nigeriaadmin.php?adm2id=NGA019002
Ogunyemi, S.A., Muibi, K. H., Eguaroje, O. E., Fabiyi, O.O. and Halilu, A.S. (2014). A geospatial approach to evaluation of accessibility to secondary educational institutions in Ogun State,Nigeria.7th International Remote sensing and GIS Conference and exhibition. IOP Conference Series: Earth and Environmental Science. pp: 12-45

Senapathi, V. and Paramasivam, C .R. (2019). An Introduction to Various Spatial Analysis Techniques. 10.1016/B978-0-12815413-7.00003-1.

Sunday, O.D. and Olayiwola, O. (2018). An assessment of public secondary school infrastructure in Osogbo, Osun state in journal of geography and planning sciences 3 (1): 112-124

Umar, H., Isma'il, M., Jaro, I., Wankata, W., Maiwada, A. (2016). Spatial Analysis of Distribution of Secondary Schools in Giwa Zone of Kaduna State in international journal of science for global sustainability 2(4):102-112 